\title{
Desain Sensor Tingkat Kekeruhan Air Menggunakan Bahan Fiber Optik
}

\author{
Silviana Dewi Masitoh¹, Yoyok Heru Prasetyo Isnomo², Lis Diana Mustafa ${ }^{3}$ \\ 1,2 Program Studi Jaringan Telekomunikasi Digital, \\ Jurusan Teknik Elektro, Politeknik Negeri Malang, Indonesia \\ ${ }^{3}$ Program Studi Teknik Telekomunikasi, \\ Jurusan Teknik Elektro, Politeknik Negeri Malang, Indonesia \\ 1illviana.dm@gmail.com, ${ }^{2}$ yoyok.heru@polinema.ac.id, ${ }^{3}$ lisdianamustafa16@gmail.com
}

\begin{abstract}
The importance of knowing the level of turbidity of water, especially in the activity of using drinking water in the form of clean water, requires a tool to be used to measure the level of turbidity of water. The use of optical fiber to determine the level of turbidity of water from the value of power loss is expected to be a solution to determine the level of turbidity of water before use. The research was conducted by measuring the value of power loss at the two ends of singlemode and multimode optical fiber connected to a fiber coupler, then measured using a Handheld Light Source and Optical Power Meter. The fiber coupler is modified by giving a 1mm hole at the center point to pass the tested water. Measurements were carried out with the condition of two optical ends without distance, the optical end was spaced $1 \mathrm{~mm}$ apart, the optical end was spaced $1 \mathrm{~mm}$ through clear water and water with a clouding agent in the form of ink. The largest measurement loss was obtained in singlemode optical fiber with a yellow color effect of 1.9dB. In multimode optical fiber, the yellow color cloud is $2.81 d B$. The results of the graph and calculation of power loss show the effect of adding an ink clouding agent to the measured power in the OPM. Based on the measurement results of changes in power loss that are not constant for each addition of 5 ml of turbidity, the sensor designed has low sensitivity.
\end{abstract}

Keywords - Fiber Optic, Fiber Optic Sensor, Fiber Optic Turbidity Sensor.

\begin{abstract}
Abstrak - Pentingnya mengetahui tingkat kekeruhan air terutama dalam aktivitas penggunaan air konsumsi yang berupa air bersih menuntut adanya suatu alat yang digunakan untuk mengukur tingkat kekeruhan air. Pemanfaatan serat optik untuk mengetahui tingkat kekeruhan air dari nilai rugi daya diharapkan dapat menjadi suatu solusi untuk mengetahui tingkat kekeruhan air sebelum digunakan. Penelitian dilakukan dengan mengukur nilai loss daya pada dua ujung serat optik singlemode dan multimode yang dihubungkan dengan fiber coupler, kemudian diukur menggunakan Handheld Light Source dan Optical Power Meter. Fiber coupler dimodifikasi dengan memberi lubang sebesar $1 \mathrm{~mm}$ pada titik tengah untuk melewatkan air yang diuji. Pengukuran dilakukan dengan kondisi dua ujung optik tanpa jarak, ujung optik diberi jarak sebesar 1mm, ujung optik diberi jarak sebesar 1mm melalui air jernih dan air dengan zat pengeruh berupa tinta. Didapatkan hasil loss pengukuran terbesar pada serat optik singlemode dengan pengeruh warna yellow sebesar 1.9dB. Pada serat optik multimode pengeruh warna yellow sebesar $2.81 \mathrm{~dB}$. Hasil grafik dan perhitungan loss daya menggunakan matlab menunjukkan adanya pengaruh penambahan zat pengeruh tinta terhadap daya terukur di OPM. Berdasarkan hasil pengukuran perubahan loss daya tidak konstan pada setiap penambahan $5 \mathrm{ml}$ zat pengeruh, dapat dikatakan sensor yang di desain memiliki sensitivitas rendah.
\end{abstract}

Kata kunci- Fiber Optik, Sensor Fiber Optik, Sensor Kekeruhan Fiber Optik.

\section{PENDAHULUAN}

Air merupakan komponen utama yang tidak dapat dipisahkan dengan kehidupan manusia, berbagai aktivitas manusia tidak lepas dengan adanya air. Sebagai sumber kehidupan utama, air menjadi kebutuhan pokok yang harus terpenuhi. Kebutuhan manusia akan air terutama untuk dikonsumsi, mencuci, memasak hingga sebagai pembangkit listrik tidak lepas oleh peranan air.

Namun seiring dengan penggunaan air untuk berbagai aktivitas menimbulkan dampak yang cukup serius bagi manusia [1]. Masalah utama yang sering ditemui adalah akibat dari pembuangan limbah cair yang berdampak buruk bagi lingkungan dan Kesehatan [2]-[3]. Pembuangan limbah cair tidak hanya disumbang oleh limbah industri namun juga pembuangan limbah domestik atau limbah rumah tangga secara langsung ke lingkungan [4]. Menurut data statistik Kementerian Lingkungan Hidup dan Kehutanan (KLHK) tahun 2018, 25,1 persen sungai di Indonesia mengalami pencemaran air[1]. Hal ini menunjukkan bahwa pencemaran yang terjadi cukup parah.

Serat optik merupakan suatu media transmisi yang terbuat dari kaca maupun plastik yang mentransmisikan sinyal berupa cahaya [5]. Pada umumnya sumber cahaya yang digunakan untuk pentransmisian pada serat optik adalah laser [6]. Kabel serat optik akan memantulkan dan membiaskan sejumlah cahaya yang merambat didalamnya. Kabel serat optik juga memiliki keunggulan untuk dapat bertahan pada banyak gangguan seperti kelembaban udara dan panas. Serat optik tidak mudah terbakar dan tidak mengalirkan listrik sehingga penggunaannya lebih aman. 
Dalam perkembangannya serat optik dapat dimanfaatkan sebagai sensor. Penggunaan serat optik sebagai sensor telah banyak dilakukan. Penelitian yang telah dilakukan yakni pengukuran perubahan indek bias cahaya pada serat. Pengukuran menggunakan indeks bias yang sudah dikembangkan yakni menggunakan serat optik sebagai sensor dengan fiber coupler. Prinsip kerja sensor berdasarkan pemantulan Fresnel yang terjadi pada ujung kanal sensing yang bersentuhan dengan zat cair. Perubahan indeks bias zat cair akan mempengaruhi besarnya intensitas cahaya yang terpantul menuju detektor optis melalui kanal deteksi fiber coupler [4]. Oleh sebab itu pada penelitian ini dilakukan pemanfaatan dan analisis serat optik sebagai sensor untuk mengetahui kekeruhan air. Dua ujung serat optik dihubungkan menggunakan fiber coupler dan diberi jarak dalam orde millimeter. Jarak antar ujung serat optik akan diberi beberapa medium, seperti udara, air jernih, air yang dilarutkan dengan tinta dengan beberapa warna yakni yellow,magenta, cyan dan black nilai yang terukur akan digunakan sebagai acuan kekeruhan air yang terukur dan kemudian akan disajikan dalam bentuk grafik.

\section{METODE}

\section{A. Rancangan Penelitian}

Pada rancangan penelitian ini dijelaskan langkah - langkah penelitian secara umum yang menggambarkan tahapan proses penelitian dari awal hingga didapatkan kesimpulan dari penelitian.

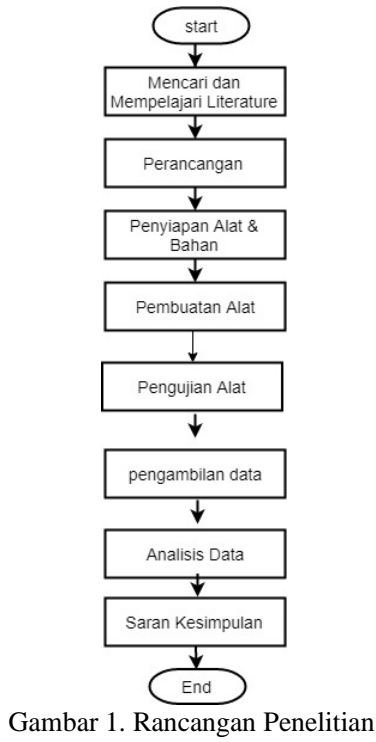

\section{B. Populasi}

Populasi adalah wilayah generalisasi yang terdiri dari obyek atau subyek yang menjadi kuantitas dan karakteristik tertentu yang diterapkan oleh peneliti untuk dipelajari dan kemudian ditarik kesimpulannya. Populasi pada penelitian ini adalah air keruh yang memiliki warna dan tingkat kekeruhan berbeda. Air dikatakan keruh apabila memiliki warna, rupa dan zat tersuspensi yang menimbulkan sifat keruh pada air.

\section{Sampel dan Teknik Pengambilan Sampel}

Pada penelitian ini sampel atau zat uji yang digunakan adalah air yang dilarutkan dengan tinta printer merk HP. Warna tinta yang digunakan sebagai zat pengeruh dan dilarutkan ke dalam air yakni yellow, magenta, cyan dan black. Keempat warna tinta tersebut diambil sebanyak $5 \mathrm{ml}$ untuk dilarutkan ke dalam air sebanyak 500ml dan dilakukan pengukuran. Selanjutnya tinta ditambahkan tiap $5 \mathrm{ml}$ hingga dilakukan percobaan sebanyak 30 kali dengan volume tinta $150 \mathrm{ml}$.

\section{Data-Data dalam Penelitian}

Data yang diperlukan dalam menunjang penelitian ini adalah Data Primer dan Data Sekunder. Data Primer diperlukan untuk perhitungan dan analisis sedangkan data sekunder diperlukan untuk mendukung data primer dalam mengkaji penelitian yang telah dilakukan. Data Primer : Merupakan data hasil pengukuran dari penelitian berupa nilai rugi daya hasil keluaran dari kabel jenis singlemode dan multimode. Data Sekunder : merupakan data dari teori penunjang yang serupa dan mendukung penelitian sebagai dasar dalam setiap hasil penelitian seperti buku, jurnal, penelitian terdahulu, artikel, internet dan forum-forum resmi mengenai spesifikasi alat.

\section{E. Teknik Analisis atau Pengolahan Data}

Analisis dilakukan dengan dua metode yakni analisis statistik dan analisis menggunakan neural network. Pada analisis statistik yakni dengan melakukan regresi linier sederhana terhadap hasil data yang diperoleh dari pengukuran. Metode analisis yang kedua yakni analisis menggunakan Neural Network, analisis ini dilakukan pada software matlab.

\section{F. Perancangan}

Rancangan penelitian meliputi perancangan alat, dan pengukuran yang dilakukan untuk memperoleh data loss daya yang dipengaruhi oleh air keruh. Berikut merupakan gambar desain Fiber Coupler yang digunakan sebagai sensor:

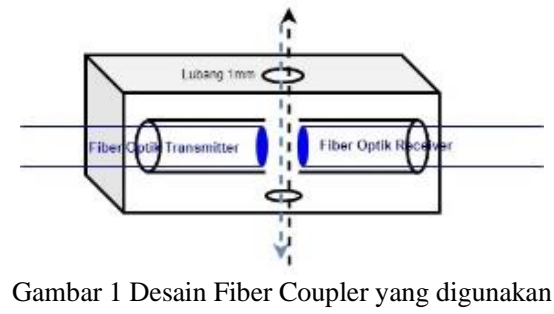

Penggunaan fiber coupler dalam rancangan ini digunakan dengan tujuan agar dapat memperoleh hasil sensing yang optimal. Berikut merupakan gambar implementasi modifikasi pada fiber coupler yang diberi lubang sebesar 1mm:

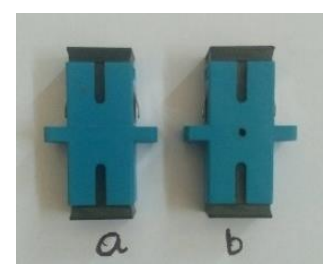

Gambar 2 Implementasi Fiber Coupler yang dimodifikasi 
1) Rancangan Pengukuran Pengukuran Awal Kabel Fiber Optik

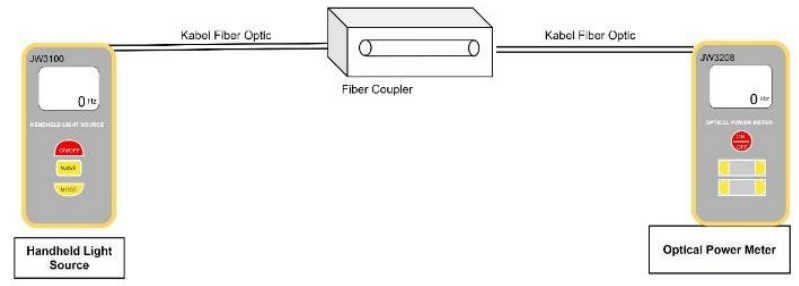

Gambar 3 Blok diagram pengukuran nilai rugi daya awal

Pada pengukuran ini, digunakan dua jenis kabel fiber optik baik multimode maupun singlemode yang dirangkai seperti gambar 4. Kabel fiber dihubungkan dengan konektor SC-SC yang belum dimodifikasi.

\section{2) Rancangan Pengukuran Daya Sebelum Fiber Coupler Dicelupkan Ke Air}

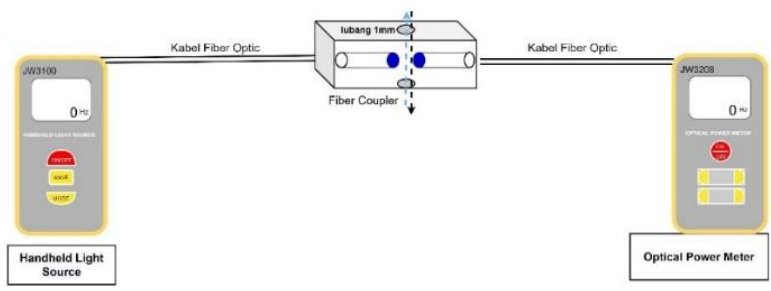

Gambar 4 Blok diagram pengukuran dengan jarak ujung serat optik 1mm

Pada pengukuran ini fiber optik baik singlemode maupun multimode dirangkai seperti gambar 5. Pengukuran ini menggunakan fiber coupler yang telah dimodifikasi, kedua ujung serat optik diberi jarak sebesar $1 \mathrm{~mm}$ sesuai dengan besar lubang pengeboran pada fiber coupler.

3) Rancangan Pengukuran Rugi Daya Pada Air Jernih dan Air Keruh
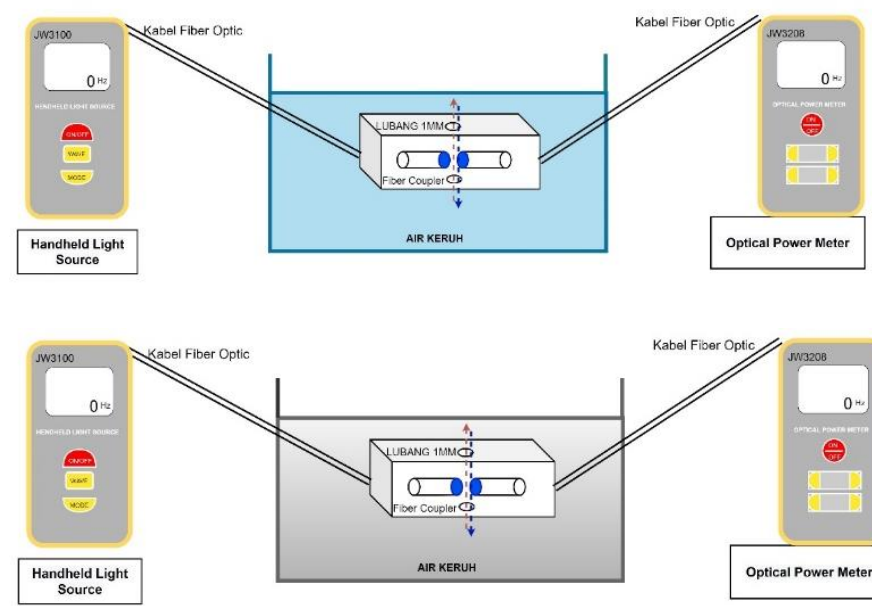

Gambar 5 (a) Fiber coupler dicelupkan pada air jernih (b) Fiber coupler dicelupkan pada air keruh
Pada pengukuran ini fiber optik baik singlemode maupun multimode dirangkai seperti gambar 6. Fiber coupler yang telah dirangkai dengan fiber optik dimasukkan ke dalam cawan yang berisi air jernih gambar (a), dilanjutkan dengan pengukuran sesuai gambar (b) yakni air yang diberi pengeruh.

\section{G. Penentuan Prosedur dan Parameter}

Tahapannya: (1) Prosedur pengukuran awal fiber optic; (2) Prosedur pengukuran loss daya sebelum melewati air keruh; (3) Prosedur pengukuran loss daya saat melewati air keruh; dan (4) Parameter, parameter yang digunakan pada penelitian ini adalah Loss daya dan tingkat kekeruhan sehingga dapat diketahui adanya pengaruh tingkat kekeruhan air terhadap Loss daya pada sensor fiber optik.

\section{HASIL DAN PEMBAHASAN}

A. Hasil Pengukuran pada Sensor Fiber Optik Singlemode TABEL I

Hasil Pengukuran TanPa Melewati KeKERUhan Singlemode

\begin{tabular}{lc}
\hline Kondisi Ujung Fiber Optik & Daya Terukur (dBm) \\
\hline Tanpa jarak & -9.19 \\
Jarak 1mm & -23.95 \\
Jarak 1mm melalui air jernih & -23.16 \\
\hline
\end{tabular}

Tabel 1. merupakan tabel hasil pengukuran awal sebelum pengukuran dengan air keruh. Nilai rugi daya pada kondisi Fiber Optik tanpa jarak terukur sepanjang saluran sebesar -9.19 $\mathrm{dBm}$, nilai rugi daya terukur pada saat ujung fiber optic diberi jarak $1 \mathrm{~mm}$ yakni sebesar $-23.95 \mathrm{dBm}$, dan nilai rugi daya pengukuran saat fiber coupler dimasukkan dalam air jernih sebesar $-23.16 \mathrm{dBm}$. Nilai daya $-23.16 \mathrm{dBm}$ merupakan nilai yang menjadi acuan untuk pengukuran kekeruhan air.

TABEL II

Hasil Pengukuran Loss Daya (DBM) Singlemode

\begin{tabular}{|c|c|c|c|c|c|}
\hline No & Pelarut & Pengeruh & $\begin{array}{l}\text { Volume Zat } \\
\text { Terlarut(ml) }\end{array}$ & $\begin{array}{l}\text { Daya } \\
\text { Terukur } \\
\text { di OPM } \\
(\mathrm{dBm}) \\
\end{array}$ & $\begin{array}{l}\text { Loss } \\
\text { Pengukuran } \\
\text { (dB) }\end{array}$ \\
\hline 1 & & & 5 & -23.24 & 0.08 \\
\hline 2 & & & 10 & -23.24 & 0.08 \\
\hline 3 & & & 15 & -23.24 & 0.08 \\
\hline 4 & & & 20 & -23.43 & 0.27 \\
\hline 5 & & & 25 & -23.43 & 0.27 \\
\hline 6 & & & 30 & -23.43 & 0.27 \\
\hline 7 & & & 35 & -23.43 & 0.27 \\
\hline 8 & & & 40 & -23.51 & 0.35 \\
\hline 9 & & & 45 & -23.51 & 0.35 \\
\hline 10 & & & 50 & -23.51 & 0.35 \\
\hline 11 & & & 55 & -23.63 & 0.47 \\
\hline 12 & Jernih & Tinta & 60 & -23.63 & 0.47 \\
\hline 13 & $\begin{array}{l}\text { Jernin } \\
500 \mathrm{ml}\end{array}$ & Yellow & 65 & -23.63 & 0.47 \\
\hline 14 & $500 \mathrm{ml}$ & & 70 & -23.63 & 0.47 \\
\hline 15 & & & 75 & -23.68 & 0.52 \\
\hline 16 & & & 80 & -23.68 & 0.52 \\
\hline 17 & & & 85 & -23.68 & 0.52 \\
\hline 18 & & & 90 & -23.68 & 0.52 \\
\hline 19 & & & 95 & -23.73 & 0.57 \\
\hline 20 & & & 100 & -23.73 & 0.57 \\
\hline 21 & & & 105 & -23.73 & 0.57 \\
\hline 22 & & & 110 & -23.73 & 0.57 \\
\hline 23 & & & 115 & -23.84 & 0.68 \\
\hline 24 & & & 120 & -23.84 & 0.68 \\
\hline
\end{tabular}




\begin{tabular}{lllll}
\hline No $\quad$ Pelarut & Pengeruh & $\begin{array}{l}\text { Volume Zat } \\
\text { Terlarut(ml) }\end{array}$ & $\begin{array}{l}\text { Daya } \\
\text { Terukur } \\
\text { di OPM } \\
\text { (dBm) }\end{array}$ & $\begin{array}{l}\text { Loss } \\
\text { Pengukuran } \\
(\mathbf{d B})\end{array}$ \\
\hline 25 & & -23.89 & 0.73 \\
26 & 125 & -23.89 & 0.73 \\
27 & 130 & -24.46 & 1.3 \\
28 & 135 & -24.46 & 1.3 \\
29 & 140 & -25.06 & 1.9 \\
30 & 145 & -25.06 & 1.9 \\
\hline
\end{tabular}

Pada tabel 2 ditampilkan hasil pengukuran rugi daya Fiber optic yang kedua ujungnya telah terhubung dengan fiber coupler modifikasi dimasukkan kedalam larutan tinta warna yellow. Nilai Loss pengukuran didapatkan dari selisih nilai daya yang terukur saat cahaya fiber optic melalui air jernih dikurangkan dengan daya yang terukur saat cahaya fiber optic melalui air yang terlarut dengan zat pengeruh.

$$
\begin{gathered}
\text { Loss Pengukuran }=\mathrm{P}_{\text {keruh }}-\mathrm{P}_{\text {jernih }} \\
0.08 \mathrm{~dB}=-23.16 \mathrm{dBm}-(-23.24 \mathrm{dBm})
\end{gathered}
$$

dimana Loss Pengukuran merupakan daya terukur yang sebenarnya $(\mathrm{dB})$. Pair jernih merupakan daya terukur tanpa pengeruh $(\mathrm{dBm})$. $P_{\text {keruh }}$ merupakan daya terukur dengan kekeruhan $(\mathrm{dBm})$.

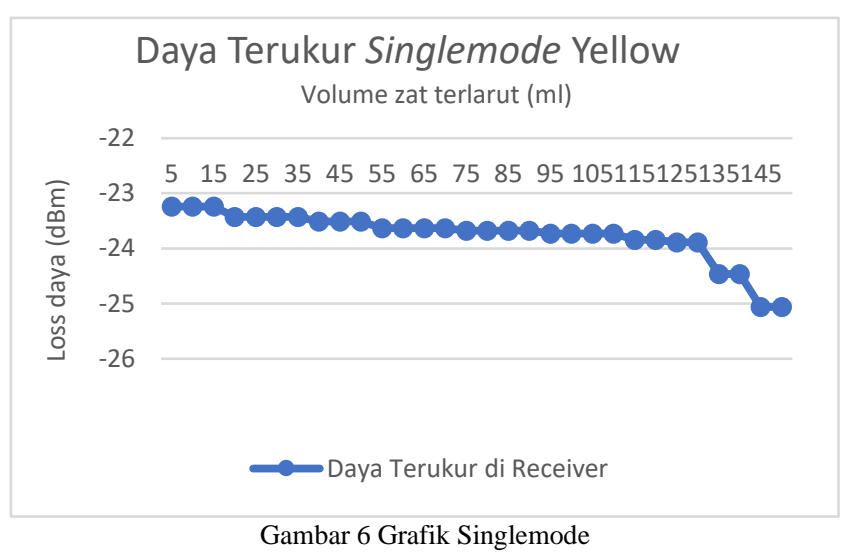

Dari grafik diatas dapat dilihat pengaruh penambahan volume zat pengeruh pada setiap percobaan mempengaruhi hasil output loss daya yang terukur pada optical power meter (OPM). Dari grafik perubahan loss daya terjadi perubahan cukup drastis yang diakibatkan penambahan volume tinta $135 \mathrm{ml}$ dan $145 \mathrm{ml}$. Dapat dilihat bahwa adanya pengaruh penambahan zat pengeruh berupa tinta terhadap pembacaan loss daya.

Selanjutnya untuk mengetahui hubungan antara loss pengukuran (x) sebagai representasi tingkat kekeruhan dengan pengeruh warna yellow dalam larutan yang diukur dengan rugi daya terukur (y) dihitung dengan menggunakan persamaan regresi linier sebagai berikut:

$$
\begin{gathered}
a=\frac{\left(\sum Y\right)\left(\sum X^{2}\right)-\left(\sum X\right)\left(\sum X Y\right)}{n \sum X^{2}-\left(\sum X^{2}\right)} \\
a=\frac{(2325)(16933.99)-(172.63)(-55713.1)}{30(16933.99)-(16933.99)} \\
a=-0.67
\end{gathered}
$$

$$
\begin{gathered}
b=\frac{\mathrm{n}\left(\sum \mathrm{XY}\right)-\left(\sum \mathrm{X}\right)\left(\sum \mathrm{Y}\right)}{n \sum X^{2}-\left(\sum X^{2}\right)} \\
b=\frac{30(-55713.1)-(-712.63)(2325)}{30(16933.99)-(16933.99)} \\
b=-0.030 \\
Y=a+b X \\
Y=-0.674-0.030 X \\
Y=-0.674-0.030 x 0.08 \\
Y=-0.6764
\end{gathered}
$$

Dari perhitungan diatas diperoleh persamaan Nilai $Y$ sebagai persamaan global $\mathrm{Y}=-0.674-0.030 \mathrm{X}$. Persamaan tersebut digunakan untuk memperoleh nilai regresi linier (Y) dengan memasukkan nilai Loss pengukuran dari setiap hasil pengukuran.

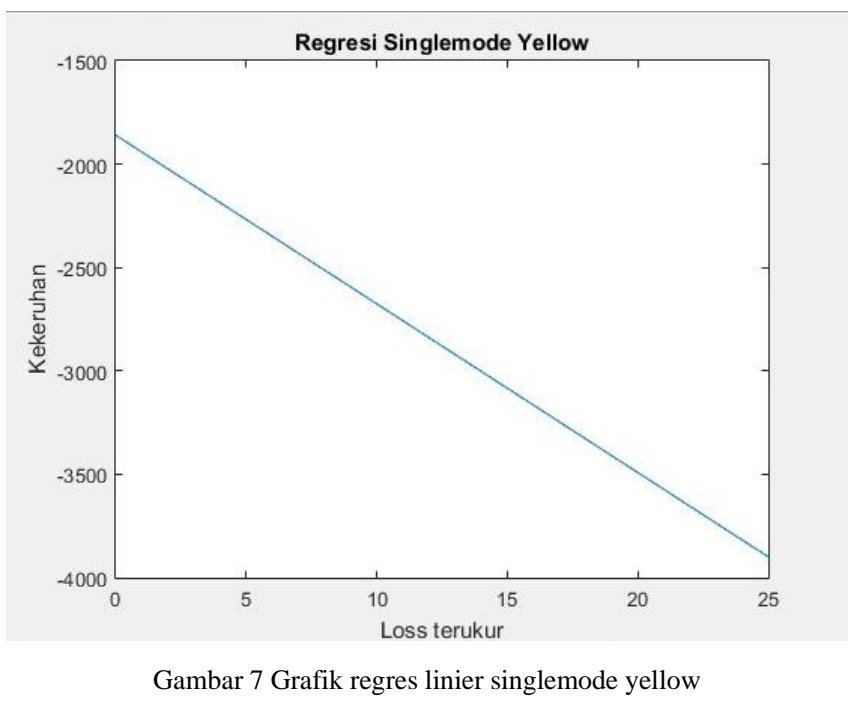

Pada gambar 8 diatas merupakan grafik hasil perhitungan regresi linier $(\mathrm{Y})$ pada singlemode dengan pengeruh warna yellow, dapat dilihat bahwa perubahan loss terukur mengalami perubahan secara linear sesuai dengan besar penambahan zat pengeruh yang diberikan. Sehingga dapat dikatakan bahwa variabel $\mathrm{X}$ berpengaruh pada variabel $\mathrm{Y}$. Hubungan antara $\mathrm{X}$ dan y dengan hasil negatif berarti setiap penambahan variable $\mathrm{x}$ yang berupa kekeruhan akan mempengaruhi nilai y akan menurun atau semakin kecil.

\section{B. Hasil Pengukuran pada Sensor Fiber Optik Multimode TABEL III}

Hasil Pengukuran Tanpa Melewati Kekeruhan Multimode

\begin{tabular}{lc}
\hline Kondisi Ujung Fiber Optik & Daya terukur di OPM (dBm) \\
\hline Tanpa jarak & -9.56 \\
Jarak 1mm & -18.07 \\
Jarak 1mm melalui air & -16.72 \\
\hline
\end{tabular}

Pada tabel diatas disajikan nilai daya yang terukur pada receiver yang diperoleh pengukuran menggunakan desain sensor yang telah dibuat, warna tinta yang digunakan, volume zat yang dilarutkan. Nilai daya awal sebesar $-9.56 \mathrm{dBm}$, nilai daya terukur pada saat ujung serat optic diberi jarak $1 \mathrm{~mm}$ yakni sebesar -18.07 dBm, dan pengukuran saat fiber coupler dimasukkan dalam air jernih sebesar $-16.72 \mathrm{dBm}$. Nilai daya - 
$16.72 \mathrm{dBm}$ merupakan nilai yang menjadi acuan untuk pengukuran kekeruhan air.

TABEL IV

Hasil Pengukuran Loss Daya (DBM) Mutimode

\begin{tabular}{|c|c|c|c|c|c|}
\hline No & Pelarut & Pengeruh & $\begin{array}{l}\text { Volume Zat } \\
\text { Terlarut(ml) }\end{array}$ & $\begin{array}{l}\text { Daya } \\
\text { terukur di } \\
\text { OPM }(\mathbf{d B m})\end{array}$ & $\begin{array}{l}\text { Loss } \\
\text { (dB) }\end{array}$ \\
\hline 1 & & & 5 & -17.36 & 0.64 \\
\hline 2 & & & 10 & -17.36 & 0.64 \\
\hline 3 & & & 15 & -17.4 & 0.68 \\
\hline 4 & & & 20 & -17.4 & 0.68 \\
\hline 5 & & & 25 & -17.4 & 0.68 \\
\hline 6 & & & 30 & -17.63 & 0.91 \\
\hline 7 & & & 35 & -17.63 & 0.91 \\
\hline 8 & & & 40 & -17.63 & 0.91 \\
\hline 9 & & & 45 & -17.89 & 1.17 \\
\hline 10 & & & 50 & -17.89 & 1.17 \\
\hline 11 & & & 55 & -17.94 & 1.22 \\
\hline 12 & & & 60 & -17.94 & 1.22 \\
\hline 13 & & & 65 & -17.94 & 1.22 \\
\hline 14 & & & 70 & -18.19 & 1.47 \\
\hline 15 & Air & Tinta & 75 & -18.19 & 1.47 \\
\hline 16 & $500 \mathrm{ml}$ & Yellow & 80 & -18.19 & 1.47 \\
\hline 17 & & & 85 & -18.24 & 1.52 \\
\hline 18 & & & 90 & -18.24 & 1.52 \\
\hline 19 & & & 95 & -18.59 & 1.87 \\
\hline 20 & & & 100 & -18.59 & 1.87 \\
\hline 21 & & & 105 & -18.79 & 2.07 \\
\hline 22 & & & 110 & -19.01 & 2.29 \\
\hline 23 & & & 115 & -19.01 & 2.29 \\
\hline 24 & & & 120 & -19.47 & 2.75 \\
\hline 25 & & & 125 & -19.47 & 2.75 \\
\hline 26 & & & 130 & -19.47 & 2.75 \\
\hline 27 & & & 135 & -19.51 & 2.79 \\
\hline 28 & & & 140 & -19.51 & 2.79 \\
\hline 29 & & & 145 & -19.51 & 2.79 \\
\hline 30 & & & 150 & -19.53 & 2.81 \\
\hline
\end{tabular}

Pada tabel 4 merupakan tabel hasil pengukuran loss daya dimana Fiber optic yang kedua ujungnya telah terhubung dengan fiber coupler modifikasi dimasukkan kedalam larutan tinta warna yellow (kuning).

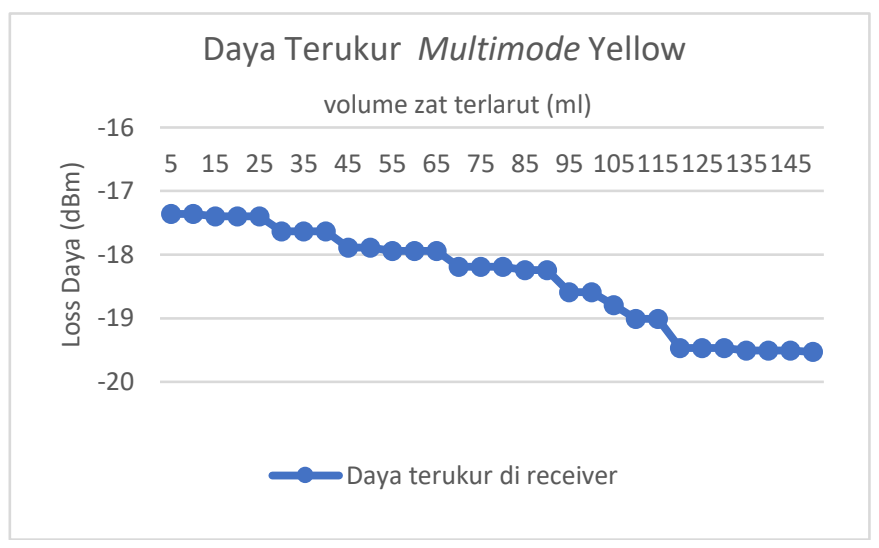

Gambar 9 Grafik Multimode

Dari grafik diatas dapat dilihat pengaruh penambahan volume zat pengeruh pada setiap percobaan mempengaruhi hasil output loss daya yang terukur pada optical power meter (OPM). Penurunan nilai loss daya terjadi pertama pada penambahan $5 \mathrm{ml}$ volume zat terlarut(pengeruh) dan selanjutnya terjadi pada $15 \mathrm{ml}, 30 \mathrm{ml}$ dan seterusnya. Dari grafik perubahan loss daya terjadi perubahan cukup drastis yang diakibatkan penambahan volume tinta $125 \mathrm{ml}$. Hal ini dapat disebabkan karena banyaknya volume zat terlarut (tinta) yang ditambahkan pada air mempengaruhi loss daya yang terbaca pada Optical Power Meter.

Selanjutnya untuk mengetahui hubungan antara loss pengukuran (x) sebagai representasi tingkat kekeruhan dengan pengeruh warna yellow dalam larutan yang diukur dengan rugi daya terukur (y) dihitung dengan menggunakan persamaan regresi linier sebagai berikut:

$$
\begin{gathered}
a=\frac{\left(\sum \mathrm{Y}\right)\left(\sum X^{2}\right)-\left(\sum \mathrm{X}\right)\left(\sum \mathrm{XY}\right)}{n \sum X^{2}-\left(\sum X^{2}\right)} \\
a=\frac{(2325)(-43669.3)-(-550.92)(-43669.3)}{30(-43669.3)-(-43669.3)} \\
\mathrm{a}=-1.684 \\
b=\frac{\mathrm{n}\left(\sum \mathrm{XY}\right)-\left(\sum \mathrm{X}\right)\left(\sum \mathrm{Y}\right)}{n \sum X^{2}-\left(\sum X^{2}\right)} \\
b=\frac{30(-43669.3)-(-43669.3)(2325)}{30(-43669.3)-(-43669.3)} \\
b=-0.099 \\
Y=a+b X \\
Y=-1.684-0.099 X \\
Y=-1.684-0.099 x 0.64 \\
Y=-1.74736
\end{gathered}
$$

Dari perhitungan diatas diperoleh persamaan Nilai Y sebagai persamaan global $\mathrm{Y}=-1.684-0.099 \mathrm{X}$. Persamaan tersebut digunakan untuk memperoleh nilai regresi linier $(\mathrm{Y})$ dengan memasukkan nilai Loss pengukuran dari setiap hasil pengukuran.

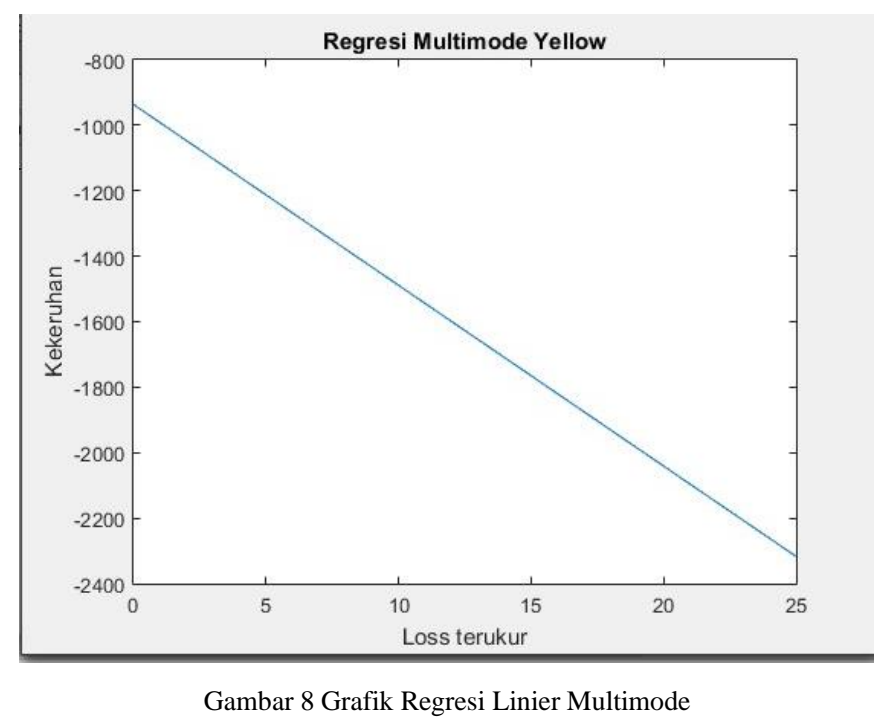

Pada gambar 10 diatas merupakan grafik regresi linier dari hasil perhitungan regresi linier untuk multimode dengan pengeruh warna yellow, dapat dilihat bahwa perubahan loss terukur mengalami perubahan secara linear sesuai dengan besar penambahan zat pengeruh yang diberikan. Sehingga dapat dikatakan bahwa variabel $\mathrm{X}$ berpengaruh pada variabel Y. Semakin bertambahnya kekeruhan maka nilai rugi daya terukur semakin menurun. 
TABEL V

TABEL ANALISIS JARINGAN SYARAF TIRUAN

\begin{tabular}{|c|c|c|c|c|c|c|}
\hline No & $\begin{array}{c}\text { Volume } \\
\text { Terlaru } \\
\text { t (ml) }\end{array}$ & $\begin{array}{l}\text { Redama } \\
\text { n }(d B) \\
\text { Singlemo } \\
\text { de }\end{array}$ & $\begin{array}{l}\text { Redam } \\
\text { an } \\
\text { (dB) } \\
\text { Multi } \\
\text { mode }\end{array}$ & $\begin{array}{l}\text { Pendeka } \\
\text { tan JST } \\
\text { (NTU) }\end{array}$ & $\begin{array}{l}\text { Penguku } \\
\text { ran } \\
\text { sensor } \\
\text { (NTU) }\end{array}$ & $\begin{array}{l}\text { Error } \\
(\%)\end{array}$ \\
\hline 1 & 5 & 0.08 & 0.64 & 0.58 & 0.44 & $\begin{array}{l}32.79 \\
\%\end{array}$ \\
\hline 2 & 10 & 0.08 & 0.64 & 1.28 & 0.81 & $\begin{array}{l}58.53 \\
\%\end{array}$ \\
\hline 3 & 15 & 0.08 & 0.68 & 1.94 & 1.71 & $\begin{array}{l}13.57 \\
\%\end{array}$ \\
\hline 4 & 20 & 0.27 & 0.68 & 2.51 & 2.61 & $4.00 \%$ \\
\hline 5 & 25 & 0.27 & 0.68 & 2.95 & 3.16 & $6.60 \%$ \\
\hline 6 & 30 & 0.27 & 0.91 & 3.28 & 3.34 & $1.68 \%$ \\
\hline 7 & 35 & 0.27 & 0.91 & 3.52 & 3.52 & $0.06 \%$ \\
\hline 8 & 40 & 0.35 & 0.91 & 3.69 & 3.61 & $2.21 \%$ \\
\hline 9 & 45 & 0.35 & 1.17 & 3.81 & 3.65 & $4.39 \%$ \\
\hline 10 & 50 & 0.35 & 1.17 & 3.90 & 3.71 & $5.25 \%$ \\
\hline 11 & 55 & 0.47 & 1.22 & 3.99 & 3.82 & $4.50 \%$ \\
\hline 12 & 60 & 0.47 & 1.22 & 4.09 & 4.24 & $3.54 \%$ \\
\hline 13 & 65 & 0.47 & 1.22 & 4.21 & 4.51 & $6.61 \%$ \\
\hline 14 & 70 & 0.47 & 1.47 & 4.36 & 4.71 & $7.34 \%$ \\
\hline 15 & 75 & 0.52 & 1.47 & 4.55 & 4.54 & $0.13 \%$ \\
\hline 16 & 80 & 0.52 & 1.47 & 4.74 & 4.65 & $2.04 \%$ \\
\hline 17 & 85 & 0.52 & 1.52 & 4.95 & 4.82 & $2.64 \%$ \\
\hline 18 & 90 & 0.52 & 1.52 & 5.14 & 4.96 & $3.63 \%$ \\
\hline 19 & 95 & 0.57 & 1.87 & 5.31 & 5.2 & $2.18 \%$ \\
\hline 20 & 100 & 0.57 & 1.87 & 5.46 & 5.46 & $0.09 \%$ \\
\hline 21 & 105 & 0.57 & 2.07 & 5.60 & 5.58 & $0.27 \%$ \\
\hline 22 & 110 & 0.57 & 2.29 & 5.71 & 5.74 & $0.53 \%$ \\
\hline 23 & 115 & 0.68 & 2.29 & 5.82 & 5.82 & $0.00 \%$ \\
\hline 24 & 120 & 0.68 & 2.75 & 5.95 & 5.92 & $0.47 \%$ \\
\hline 25 & 125 & 0.73 & 2.75 & 6.13 & 6.31 & $2.83 \%$ \\
\hline 26 & 130 & 0.73 & 2.75 & 6.43 & 6.52 & $1.41 \%$ \\
\hline 27 & 135 & 1.3 & 2.79 & 6.84 & 6.82 & $0.23 \%$ \\
\hline 28 & 140 & 1.3 & 2.79 & 7.20 & 7.12 & $1.14 \%$ \\
\hline 29 & 145 & 1.9 & 2.79 & 7.72 & 7.45 & $3.66 \%$ \\
\hline 30 & 150 & 1.9 & 2.81 & 7.79 & 7.78 & $0.14 \%$ \\
\hline \multicolumn{6}{|c|}{ Rata- Rata Error } & $5.75 \%$ \\
\hline
\end{tabular}

Dari tabel diatas, Pengaruh kekeruhan yang terjadi pada jenis kabel singlemode dan multimode yakni dari penambahan volume zat terlarut (pengeruh yellow) yang diberikan berbanding lurus dengan perubahan rugi daya yang terukur. Namun perubahan rugi daya yang terjadi tidak selamanya konstan pada setiap penambahan $5 \mathrm{ml}$ zat pengeruh. Hal ini menunjukkan bahwa sensor yang di desain memiliki nilai sensitivitas cukup rendah terhadap perubahan perlakuan kekeruhan yang diberikan, dan terjadi pada kedua jenis kabel yang digunakan. Hal ini menunjukkan bawa semakin banyak intensitas zat pengeruh yang terlarut maka daya yang terukur pada receiver semakin rendah.

Pada Gambar 11 merupakan data hasil pedekatan menggunakan Jaringan Syaraf Tiruan (JST) dengan hasil pengukuran sensor turbidity pada air 500ml yang dilarutkan dengan tinta warna yellow. Grafik tersebut merupakan acuan nilai yang digunakan untuk perbandingan dengan sensor fiber optik yang telah dibuat.

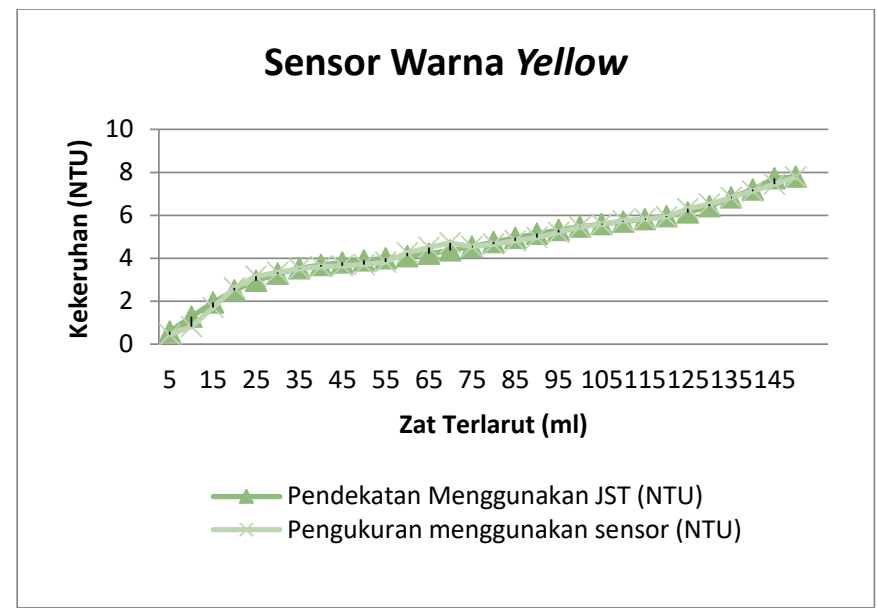

Gambar 9 Grafik Jaringan Syaraf Tiruan Sensor Multimode Yellow

\section{KESIMPULAN}

Desain sensor yang telah dirancang, dengan memanfaatkan fiber optic dan fiber coupler yang dimodifikasi dengan melakukan pengeboran sebesar $1 \mathrm{~mm}$ pada bagian tengah sebagai sensing dan diberikan variasi penambahan zat pengeruh (Tinta) sebanyak $5 \mathrm{ml}-150 \mathrm{ml}$ ke dalam 500ml air. Rugi - rugi (loss) daya yang dihasilkan setelah diberikan variasi jumlah zat pengeruh pada fiber optik singlemode lebih besar dibandingkan dengan fiber optik multimode.

\section{REFERENSI}

[1] Safitri. A. P. Statistik Lingkungan Hidup Indonesia "Pengolahan Sampah di Indonesia". 2018.

[2] Qiftia, Zilda. Sensor Indeks Bias Larutan Menggunakan Fiber Coupler, ISSN 9772337300009 Vol.2, No.2. 2014

[3] A. Arifin. Design of Sensor Water Turbidity based on Polymer Optical Fiber, Jurnal IEEE 978-1-5386-07459/17. 2017.

[4] Fatimah, Ani. Perancangan Alat Ukur TSS (Total Suspended Solid) Air Menggunakan Sensor Serat Optik Secara Real Time, ISSN 1979-4657. 2014.

[5] Maddu, Akhiruddin. Pengembangan Serat Optik dengan Cladding Termodifikasi Polianilin Nanostruktur untuk Mendeteksi Beberapa Uap Kim”. Jakarta: Disertasi Fakultas Teknik, Universitas Indonesia. 2007.

[6] Jasenek, Josef. The Theory and Aplication of Fiber Optic Sensor with Spead Parameters. Slovakia: FEI STU Bratislava. 2006. 